\title{
Solitary pleural metastasis from renal cell carcinoma: a case of successful resection
}

\author{
Masafumi Kataoka ${ }^{*}$, Yuji Yata', Sohichiro Nose ${ }^{2}$, Koichiro Yasuda ${ }^{1}$ and Toshinori Ohara ${ }^{1}$
}

\begin{abstract}
While renal cell carcinoma frequently metastasizes to the lung, solitary pleural metastasis without lung involvement is extremely rare. A 69-year-old man was admitted to our hospital with a solitary pleural metastasis 6 years after surgery for renal cell carcinoma. Needle biopsy was performed, and the tumor was diagnosed as a metastasis of renal cell carcinoma. The pleural tumor was surgically resected. The patient received interferon-a as postoperative therapy. He has been alive for 9 years without recurrence. Only 11 cases of solitary pleural metastasis have been reported thus far, and of these, 7 involved a large amount of pleural effusion resulting in a poor prognosis. This is the first reported case of solitary pleural metastasis from renal cell carcinoma, which was curatively resected, as indicated by long-term survival.
\end{abstract}

\section{Background}

Renal cell carcinoma (RCC) accounts for approximately $2 \%$ of all cancers, and nearly $50 \%$ of all RCC patients will eventually present with metastatic disease, requiring individualized treatment decision. Patients with untreated metastatic disease have a 5-year survival rate of $0 \%$ to $18 \%$ [1]. A notable feature of RCC is its tendency to result in lung metastases, which were found in 55\% of cases in an autopsy-based study [2]. Pleural metastasis is comparatively rarer than lung metastasis. Most pleural metastases are associated with metastatic lesions of the lung. Solitary pleural metastasis without lung metastasis is extremely rare. Herein, we report successful treatment by resection in a patient with a solitary pleural metastasis evidently derived from a previously removed RCC.

\section{Case presentation}

A 69-year-old man underwent a left nephrectomy for stage III 3aNOMO RCC of clear cell type in our hospital. A total of 300 units per day of interferon-alpha (IFN- $\alpha$ ) was administered for 1 year as postoperative chemotherapy. While the patient had not reported any specific complaints at 6 years post operation, chest CT revealed a $25 \times 15 \mathrm{~mm}$ irregularly shaped tumor located at the anterior chest wall, directly behind the third left rib (Figure 1). Fine-needle aspiration biopsy of the tumor was performed, and histopathological examination suggested that it was an RCC metastasis. Further examination of the abdominal $\mathrm{CT}$ and bone scintigraphy were performed to detect additional metastases. No lesions were detected in addition to the pleural metastasis.

The tumor was surgically resected in conjunction with partial resection of the third left rib and left lung. Macroscopically, the resected tumor revealed to be a $2.0 \times 1.3 \mathrm{~cm}$ yellowish tumor. Microscopically, the lesion consisted of tumor cells growing in an alveolar pattern, separated by struma, and endowed with prominent sinusoid-like vessels. These tumor cells had abundant clear cytoplasm and uniform, small, ovoid hyperchromatic nuclei. These histological features were similar to those of the previously resected RCC lesion (Figure 2). The tumor was diagnosed as being

\footnotetext{
* Correspondence: kataoka@saiseidr.jp

'Department of Surgery, Okayama Saiseikai General Hospital, 1-17-18

Ifukucho, Kita-ku, Okayama City 700-8511, Japan

Full list of author information is available at the end of the article
} 


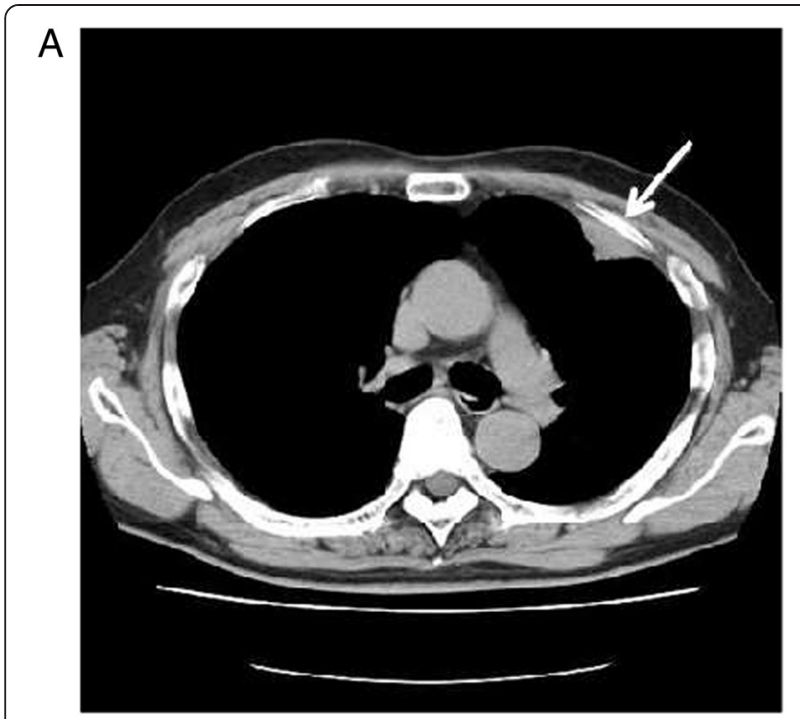

B

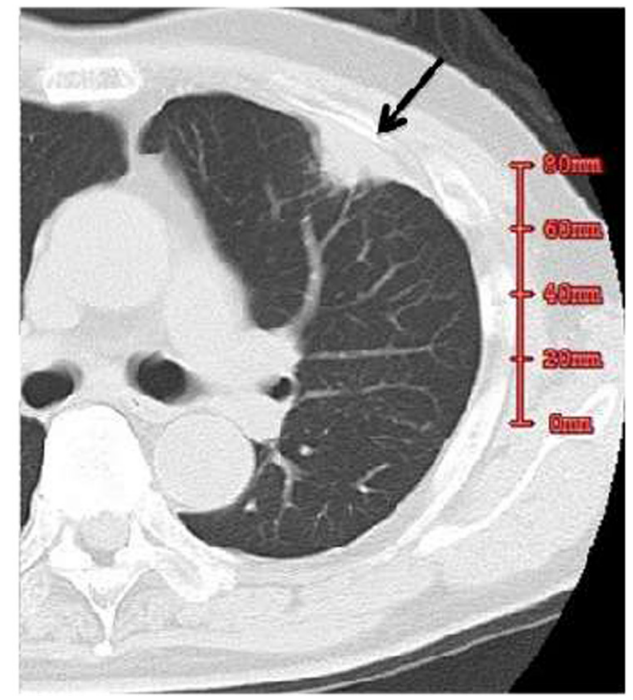

Figure 1 Computed tomography. (A) Pleural tumor is observed on the left chest wall. (B) Thin-slice CT shows the silhouette sign-positive tumor with an irregular surface. Arrows indicate the tumor at the pleura.

compatible with metastatic RCC of the pleura. The postoperative course was uneventful.

IFN- $\alpha$ was administered for 1 year as postoperative therapy. The patient has been alive for 7 years without recurrence of the carcinoma.

\section{Discussion and conclusions}

Metastasis to the lungs or mediastinum may already be present in more than one third of patients with RCC at the time of diagnosis [3]. Although RCC commonly metastasizes to the lung, pleural metastasis is rare.
Saitoh et al. [4] have investigated 1,451 autopsy cases of RCC. Of these, 979 cases (76\%) had lung metastases, and 154 cases $(12 \%)$ had pleural metastases; there were no cases of solitary pleural metastases. Kutty et al. [3] reported 25 thoracic metastases of RCC, including 7 cases of pleural metastasis, but none of these 7 cases showed solitary pleural metastasis. According to those reports, RCC spread to parietal pleurae appears to be extremely rare.

Including the case reported in this study, 14 cases of solitary pleural metastasis from RCC have been reported [5-17] (Table 1). Of these, 1 case was not reported precisely, and 7 showed a large volume of pleural effusion at the time of diagnosis. Panpleuropneumonectomy was performed on 1 patient whose cancer had recurred after surgery. The other 7 patients received chemotherapy. Cases with pleural effusion had a poor prognosis. From a literature search in PubMed and Japanese Centra Revuo Medica databases, we found that the present case is the first reported case of solitary localized pleural metastasis of RCC without pleural effusion and long-term survival after resection.

To date, there is no effective chemotherapy against RCC except interferon therapy; therefore, surgical resection is preferable for localized metastasis thereof. Takashi et al. [18] reported 21 cases of surgical resection of metastatic lesions from RCC. In that report, patients with complete resection of metastasized lesions showed favorable prognoses.

Since the metastatic lesion in our case was solitary and small, surgical resection was performed. Furthermore, the metastatic lesion was detected before the patient complained of any symptoms. By the time symptoms are evident to the patient, the extent of disease is likely to be very advanced (growth of lesion and pleural effusion) and thus incurable. Curative treatment in patients with malignant pleural effusion is quite difficult. Routine CT examination proved very useful in finding the pleural metastatic lesion at the localized stage in this case study. In the future, CT may also prove useful for the detection of lung metastases. Routine monitoring for potential chest metastases by $\mathrm{CT}$ and other methods should also be considered, in the context of 'rescue' of patients with a solitary detectable metastasis.

\section{Consent}

Witten informed consent was obtained from the patient for the publication of this case report and any accompanying images. A copy of the written consent is available for review by the Editor-in-Chief of this journal. 


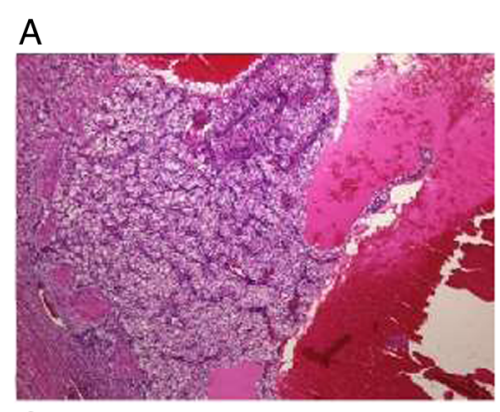

C

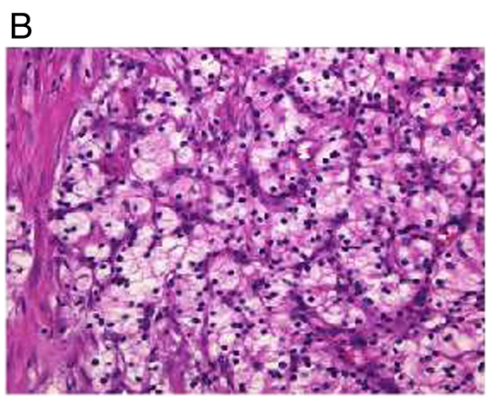

D
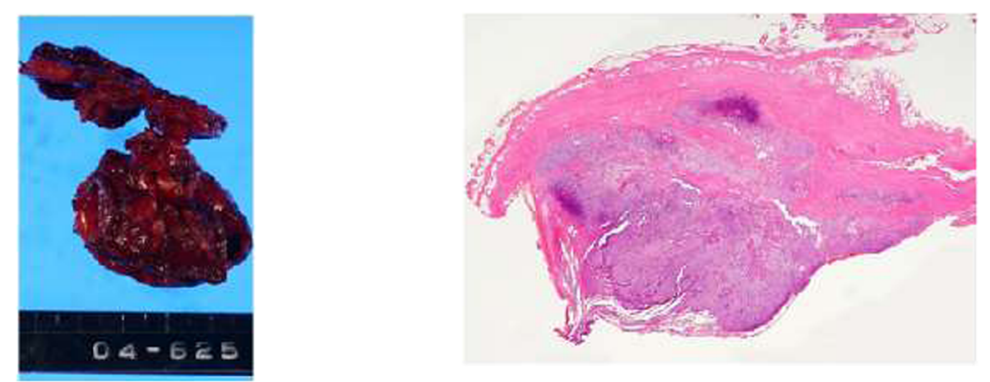

E

$\mathrm{F}$
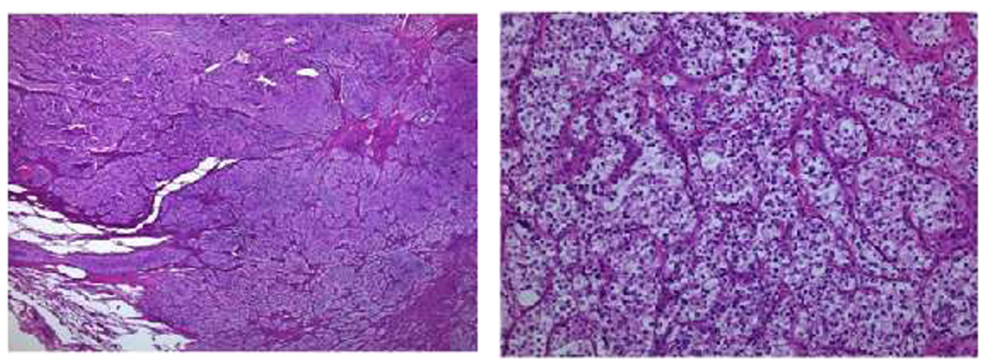

Figure 2 Microscopic findings of primary and metastatic pleural tumors. The lesion comprised tumor cells with abundant clear cytoplasm and small round nuclei with atypia in both primary tumor and metastatic tumor at the pleura (hematoxylin and eosin stain). (A) Primary lesion of the kidney (low magnification). (B) Primary lesion of the kidney (high magnification). (C) Resected tumor with rib and lung. (D) Histological specimen by magnifying glass. (E) Metastatic pleural tumor (low magnification). (F) Metastatic pleural tumor (high magnification).

Table 1 Reported cases of solitary metastasis to the pleura from renal cell carcinoma

\begin{tabular}{llllll}
\hline Reference & Age & Sex & Characteristic of lesion & Therapy & Prognosis \\
\hline Latour and Shulman [5] & Unknown & Unknown & Unknown & Unknown & Unknown \\
Taylor et al. [6] & 69 & M & Pleural tumor with huge pleural effusion & BSC & Dead at 4 months \\
Ishida et al. [7] & 71 & M & Pleural tumor with huge pleural effusion & BSC & Dead at 2 months \\
Yamasaki et al. [8] & 61 & M & Pleural tumor with huge pleural effusion & Unknown & Unknown \\
Nakamura et al. [9] & 50 & M & Pleural tumor with huge pleural effusion & Operation & Unknown \\
Azuma et al. [10] & 74 & M & Pleural tumor with pleural effusion & Unknown & Dead at 3 months \\
Ohnishi et al. [11] & 66 & M & Huge pleural effusion & IFNa & Unknown \\
Kamiyoshihara et al. [12] & 68 & M & Pleural tumor with huge pleural effusion & IFNa/RT & Dead at 15 months \\
Mizunuma et al. [13] & 59 & M & Pleural tumor with huge pleural effusion & BSC & Dead at 2 months \\
Kragel and Wei [14] & 58 & M & Metastasis to solitary fibrous tumor of the pleura & Operation & Dead at 6 months \\
Kang et al. [15] & 51 & M & Pleural tumor with pleural effusion & Unknown & Unknown \\
Sun et al. [16] & 50 & M & Multiple nodules with pleural effusion & Chemotherapy & Alive at 8 months \\
Yoshii et al. [17] & 67 & M & Pleural tumor with huge pleural effusion & Chemotherapy & Alive at 10 months \\
Our case & 75 & M & Pleural tumor & Operation & Alive at 92 months \\
\hline
\end{tabular}

BSC, best supportive care; RT, radiation therapy. 


\section{Competing interests}

The authors declare that they have no competing interests.

\section{Authors' contributions}

MK, the first author of this manuscript, performed this operation and followed the patient's progress at our hospital as an outpatient and wrote this manuscript. YY presented this case at a conference in Japanese with some discussions. His presentation is the main source of this manuscript. SN investigated this case pathologically. MK discussed the case with KY, who was the attending doctor at our hospital's inpatient ward, and discussed the content of this manuscript. TO was the head of our department and also assisted this operation. All authors read and approved the final manuscript.

\section{Author details}

${ }^{1}$ Department of Surgery, Okayama Saiseikai General Hospital, 1-17-18 Ifukucho, Kita-ku, Okayama City 700-8511, Japan. ²Department of Pathology, Okayama Saiseikai General Hospital, 1-17-18 Ifukucho, Kita-ku, Okayama City 700-8511, Japan.

Received: 15 February 2015 Accepted: 9 April 2015

\section{Published online: 23 April 2015}

\section{References}

1. Hofmann HS, Neef H, Krohe K, Andreev P, Silber RE. Prognostic factors and survival after pulmonary resection of metastatic renal cell carcinoma. Eur Urol. 2005;48:77-81.

2. Bennington $J$, Kradjian RM. Distribution of metastases from renal carcinoma. In: Bennington JL, Kradjian RM, editors. Renal carcinoma. Philadelphia: WB Saunders Co; 1967. p. 156-7. chap 6.

3. Kutty K, Varkey B. Incidence and distribution of intrathoracic metastases from renal cell carcinoma. Arch Inter Med. 1984;144:273-6.

4. Saitoh H. Distant metastasis of renal adenocarcinoma. Cancer. 1981;48:1487-91.

5. Latour A, Shulman HS. Thoracic manifestation of renal cell carcinoma. Diagn Radiol. 1976;121:43-8.

6. Taylor DR, Page W, Hughes D, Varghese G. Metastatic renal cell carcinoma mimicking pleural mesothelioma. Thorax. 1987;42:901-2.

7. Ishida T, Nakamura A, Kiyotani T, Fukuse T, Wazawa H, Tamada J. A case of renal cell carcinoma with metastasis mimicking malignant pleural mesothelioma (Japanese). Jpn J Lung Cancer. 1990;30:289-94.

8. Yamazaki K, Takaoka K, Matsuda M. A case of renal cell carcinoma detected with massive pleural effusion and developed into intrathoracic metastasis mimicking malignant pleural mesothelioma (Japanese). Resp Res. 1992;11:628-33.

9. Nakamura T, Sekine T, Kosaba S. A case of surgical resection of renal cell carcinoma with intrathoracic metastasis (Japanese). J Jpn Assn Thorac Surg. 1996;44:1800-4.

10. Azuma T, Nishimatsu H, Nakagawa Tomita K, Takeuchi T, Homma Y, et al Metastatic renal cell carcinoma mimicking pleural mesothelioma. Scand J Urol Nephrol. 1999:33:140-1.

11. Ohnishi H, Abe M, Hamada H, Yokoyama A, Hirayama T, Ito R, et al. Metastatic renal cell carcinoma presenting as multiple pleural tumors. Respirology. 2005;10:128-31.

12. Kamiyoshihara M, Takise A, Itou H, Takeyoshi I. Pleural metastases from renal cell carcinoma 16 years after resection. J Clin Oncol. 2007;25:4009-11.

13. Mizunuma K, Tatsukawa Y, Watanabe H, Mori M, Motoi M. A case of renal cell carcinoma with pleural metastasis mimicking malignant pleural mesothelioma in a patient on maintenance hemodialysis (Japanese). J Hiroshima Med Assoc. 2010:3:406-9.

14. Kragel C, Wei S. Renal cell carcinoma metastasizing to solitary fibrous tumor of the pleura: a case report. J Med CASE Rept. 2011;5:248

15. Kang RY, Jhun BW, Jeon K, Koh W-J, Suh GY, Chung MP, et al. Histopathologic diagnosis of pleural metastasis of renal cell carcinoma using endobronchial ultrasound-guided transbronchial needle aspiration. Tuberc Respir Dis. 2011;71:355-8.

16. Sun XF, Huang H, Xu ZJ, Li J, Xu K. Renal cell carcinoma presents as pleura metastasis without pulmonary involvement. Chin Med J. 2012;125:3193-4.
17. Yoshii Y, Kaneko Y, Gochi M, Saito Z, Samejima T, Seki A, et al. Medical thoracoscopy performed under local anesthesia is useful diagnosing pleural metastasis of renal cell carcinoma. Intern Med. 2013;52:1203-5.

18. Takashi M, Takagi Y, Sakata T, Shimoji T, Miyake K. Surgical treatment of renal cell carcinoma metastases: prognostic significance. Int Urol Nephrol. 1995;27:1-8.

\section{Submit your manuscript to a SpringerOpen ${ }^{\circ}$ journal and benefit from:}

- Convenient online submission

- Rigorous peer review

- Immediate publication on acceptance

- Open access: articles freely available online

- High visibility within the field

- Retaining the copyright to your article

Submit your next manuscript at $>$ springeropen.com 